\title{
Metabolic effects of dopamine agonists in patients with prolactinomas: a systematic review and meta-analysis
}

\author{
Sarah Byberg ${ }^{1}$, Jesper Futtrup ${ }^{2}$, Mikkel Andreassen ${ }^{1}$ and Jesper Krogh ${ }^{1}$ \\ ${ }^{1}$ Department of Medical Endocrinology, Copenhagen University Hospital, Copenhagen, Denmark \\ 2Panum Institute, Faculty of Health and Medical Sciences, University of Copenhagen, Copenhagen, Denmark \\ Correspondence should be addressed to S Byberg: sarah.byberg.01@regionh.dk
}

\begin{abstract}
Objectives: Recent large cohort studies suggest an association between high plasma prolactin and cardiovascular mortality. The objective of this systematic review was to systematically assess the effect of reducing prolactin with dopamine agonist on established cardiovascular risk factors in patients with prolactinomas.

Design: Bibliographical search was done until February 2019 searching the following databases: PubMed, EMBASE, WHO and LILAC. Eligible studies had to include participants with verified prolactinomas where metabolic variables were assessed before and after at least 2 weeks treatment with dopamine agonists.

Methods: Baseline data and outcomes were independently collected by two investigators. The study was registered with PROSPERO (registration number CRD42016046525).

Results: Fourteen observational studies enrolling 387 participants were included. The pooled standardized mean difference of the primary outcome revealed a reduction of $\mathrm{BMI}$ and weight of $-0.21\left(95 \% \mathrm{Cl}-0.37\right.$ to $\left.-0.05 ; P=0.01 ; \ell^{2}=71 \%\right)$, after treatment. Subgroup analysis suggested that the reduction of weight was primarily driven by studies with high prolactin levels at baseline $(P=0.04)$. Secondary outcomes suggested a small decrease in waist circumference, a small-to-moderate decrease in triglycerides, fasting glucose levels, HOMA-IR, HbA1c and hsCRP, and a moderate decrease in LDL, total cholesterol and insulin.

Conclusion: This systematic review suggests a reduction of weight as well as an improved lipid profile and glucose tolerance after treatment with dopamine agonist in patients with prolactinomas. These data are based on low-quality evidence.
\end{abstract}

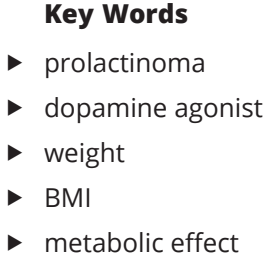

Endocrine Connections (2019) 8, 1395-1404

\section{Introduction}

In recent large cohort studies, high prolactin levels within and above the normal physiological range have been associated with increased risk of cardiovascular mortality $(1,2,3)$. It is speculated whether this association is mediated through prolactin-induced increase in cardiovascular risk factors including obesity, dyslipidemia and insulin resistance $(4,5,6,7,8,9,10)$. In a German populationbased cohort study, prolactin levels within the normal range showed a positive correlation to all-cause as well as cardiovascular mortality (1). Furthermore, prolactin levels prospectively correlated with higher levels of low-density lipoprotein (LDL) in women, and with hypertension and incidence of diabetes in men (11). In two large cohort studies hyperprolactinemia was associated with increased incidence of cardiovascular disease and cardiovascular mortality in men only $(2,3)$. However, the association between prolactin and excess disease burden is not consistent: In a case-control study with 1204 cases of

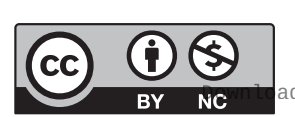

This work is licensed under a Creative Commons Attribution-NonCommercial 4.0 International License. ded from Bioscientifica.com at 04/26/2023 06:57:23AM 
hyperprolactinemia, no increased morbidity or mortality was found (12), and in a large cohort, levels of prolactin did not differ between those participants who suffered from fatal or nonfatal coronary artery disease and those who did not (13).

Prolactin receptors are widely distributed in the liver (14), endocrine pancreas (15) and in adipose tissue (16) pointing to a possible direct metabolic effect of prolactin. A number of small studies have found that prolactin levels are associated with inflammation, endothelial dysfunction, insulin resistance and dyslipidemia that could contribute to cardiovascular complications $(7,17,18,19$, 20). Furthermore, prolactin levels correlated with insulin resistance in patients with polycystic ovary syndrome (21).

Dopamine is the natural negative regulator of prolactin release from the anterior pituitary gland, and dopamine D2 receptor agonists are the first line of treatment for most patients with prolactinoma.

A link between high prolactin levels and cardiovascular mortality would have important clinical implications. According to current guidelines (22), asymptomatic patients with hyperprolactinemia are not necessarily offered treatment; the same is true for secondary hyperprolactinemia as a side effect to widely used medications, such as antipsychotic drugs or in patients with kidney failure.

The purpose of this systematic review was to systematically assess the metabolic effects of dopamine agonist treatment in patients with prolactinomas.

\section{Methods}

\section{Study design}

A systematic review and meta-analysis. The study was registered with PROSPERO (registration number CRD42016046525).

\section{Study selection}

Eligible studies were observational or randomized clinical trials assessing the effect of dopamine agonist treatment in patients with prolactinomas verified by MRI or CT scan. For inclusion, the studies should report on metabolic variables before and after dopamine-agonist treatment. Patients should have been treated with dopamine agonist for more than 2 weeks. Studies that included patients with other treatments for prolactinomas, for example, surgical resection or radiotherapy of the pituitary adenoma were not included. There was no age or language restriction.

\section{Search strategy}

The following bibliographical databases were searched until February 2019: PubMed, EMBASE, WHO and LILAC using the text words terms: (prolactin OR hyperprolactinemia OR prolactinoma) AND (dopamine agonist OR dostinex OR cabergoline OR bromocriptine). The search was restricted to titles.

One investigator (SB) conducted the main search. Based on title and abstract, obviously irrelevant titles were removed and the remaining studies were considered for inclusion after thorough review of the full manuscript.

\section{Data extraction}

Demographical data, baseline data of participants, study outcomes, diagnostic procedures, patient co-morbidity, hormone replacement among participants, type and duration of treatment, and results were independently collected by two investigators (SB, JF). In studies where more than one follow-up was reported, data from the latest follow-up, where the number and gender distributions of participants were reported, were included in the analysis.

Authors were contacted by mail in case of queries regarding reported data. Two requests were sent with 14-days interval if no response was received after the first request.

\section{Outcomes}

\section{Primary outcome}

The primary outcome was change in weight or body mass index (BMI) from baseline to the end of the observation.

\section{Secondary outcomes}

Secondary outcomes were waist circumference (WC), total cholesterol, low-density lipoprotein (LDL), triglycerides (TRG), fasting plasma glucose, HOMA-IR, fasting serum insulin, glycated hemoglobin (HbA1c), plasma testosterone, luteinizing hormone (LH), folliclestimulating hormone (FSH), high-sensitivity C-reactive protein (hsCRP) and systolic and diastolic blood pressure.

\section{Assessment of study quality}

The risk of bias in the included studies was assessed by using the Newcastle-Ottawa Scale (NOS) for cohort studies as suggested by the Cochrane collaboration (23), which assesses selection bias, comparability and outcome modified for the current systematic review. Selection of

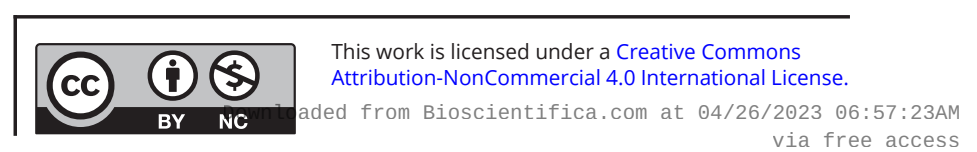


cases was awarded points if patients were consecutively approached for inclusion, if both genders were included in the study and if hypothyroidism was ruled out. In the outcome domain we assessed if the staff assessed weight or if weight was reported by the participants themselves, if staff were blinded to baseline weight and if attrition were less than 5\% at follow-up. For each study, we assessed the above items providing each with assessment of 'yes' or 'no'. In case there was inadequate information to judge either 'yes' or 'no' we used 'unclear'. The total risk of bias score was based on one point for each 'yes' in the selection bias domain or the outcome domain. We also included whether the study was conducted prospectively or retrospectively. We considered this item as posing a risk of random error opposed to a systematic error, which was assessed in the selection bias domain and the outcome domains and did not include this item in the total score which represents an estimated pooled risk of bias. Studies with a total score of 4 or more were considered with less risk of bias.

\section{Statistical methods}

For all outcomes we reported the pooled effect estimates using the standardized mean difference (SMD). SMD is the mean difference in outcome between the post- and preintervention assessment divided by the pooled standard deviation (SD). The result is a unit free effect size and by convention, SMD of 0.2, 0.5 and 0.8 are considered small, medium and large effects sizes.

In case mean $(\bar{x})$ was not reported, we calculated the mean from median $(\mathrm{m})$ and range $(\mathrm{a}-\mathrm{b})$ using the formula $\overline{\mathrm{x}} \approx(\mathrm{a}+2 \mathrm{~m}+\mathrm{b}) / 4$, as proposed by Hozo et al. (24), and $\mathrm{SD}=(\mathrm{b}-\mathrm{a}) / 4$. In case results were reported separately for men and women, a pooled mean and SD was calculated as recommended in Cochrane Handbook for Systematic Reviews (23).

We expected some degree of heterogeneity due to differences in population, duration of treatment and dose of DA, and we a priori planned to use random-effects analysis to pool estimates from included studies.

$P$ values below 0.05 were considered significant.

For data analyses, we used Comprehensive MetaAnalysis 2.0. The heterogeneity for each outcome was reported as $I^{2}$.

\section{Subgroup analysis}

For the primary outcomes, weight and BMI, we planned to explore the potential effect of confounding variables: duration of treatment ( $<6$ months was short duration of treatment vs duration of treatment of $\geq 6$ months), percentage of included men, prolactin levels at baseline, percentage of macroprolactinoma, the effect of study design as well as the effect of risk of bias. The division of groups for subgroup analysis was based on the median value.

\section{Deviation from the protocol}

There have been some changes from the original protocol: the duration of treatment was found to be equivalent to follow-up in the included studies; therefore, no subgroup analysis on follow-up was performed. Comorbidities were an exclusion criterion in seven studies and were not reported in five studies, and as a result of the inconsistency in this data point, a subgroup analysis on comorbidities was not performed. Only three studies reported change of testosterone levels $(6,25,26)$ or estradiol levels $(25,27$, $28)$, which is why this subgroup analysis was abandoned. Mixed treatment modalities were added as exclusion criteria to the original protocol. In the data analysis we conducted subgroup analysis by study design and risk of bias in addition to the original protocol. To improve the clinical applicability of the analysis, the effect sizes are also presented as mean difference.

\section{Results}

\section{Study selection and characteristics}

The bibliographical search was conducted until February 2019. As illustrated in Fig. 1, we included 14 observational studies assessing the effect of dopamine agonist therapy on metabolic variables in 387 patients with prolactinomas $(4,5,6,7,8,25,26,27,28,29,30,31,32,33)$.

As shown in Table 1, nine of the included studies were prospective $(5,7,8,26,27,28,29,30,32)$, three studies $(4,25,33)$ were retrospective and in two studies the design was not clearly stated $(6,31)$. As shown in Table 2 , study participants were treated with cabergoline $(\mathrm{CAB})$ in eight studies $(4,5,7,25,26,27,30,33)$, bromocriptine (BRC) in two studies $(28,31)$ and in four studies participants received either $\mathrm{CAB}$ or $\mathrm{BRC}(6,8,29,32)$.

The median percentage of male participants was $23 \%$ (range, $0-100 \%$ ). The median of mean age was 37 years (range, 27-42 years). The median percentages of study participants with macroprolactinoma were $31.5 \%$ (range, 13-78\%). The range of mean plasma prolactin was $2514-43,693 \mathrm{mU} / \mathrm{L}$ and the median follow-up time was 6 months (range, 3-60 months). The median number 

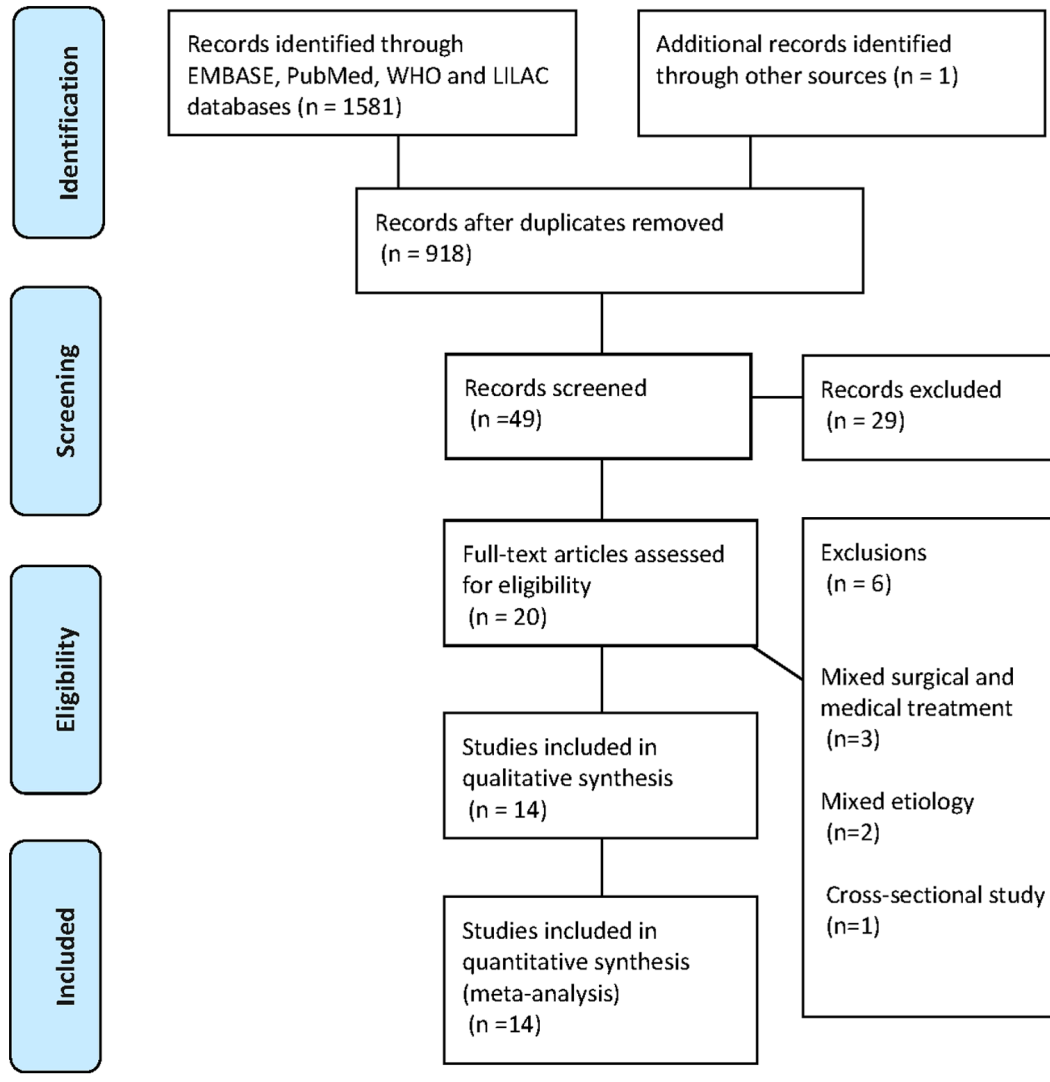

of participants that reached normoprolactinemia at follow-up was 97\% (range, 56-100\%) $(4,5,6,7,8,26,27$, $28,29,30,32$ ).

Because of heterogeneity in reported data, it has not been possible to compare the data regarding treatment dosage: In two studies the dosage was not reported $(8$, $29)$; two studies reported the initial dosage $(27,30)$, two studies reported a range of doses administered, without reporting a median dose $(28,31)$; one study reported the accumulated dose of $108 \mathrm{mg} \mathrm{CAB}$ administered over a mean period of $56.9 \pm 46$ months (33) and four studies reported doses administered in different periods of the studies $(4,5,7,26)$.

Raw data are presented in Supplementary Tables 3, 4, 5,6 , and 7 (see section on supplementary data given at the end of this article.

In the nine studies reporting obesity at baseline, the median percentage of participants with overweight at baseline was 47\% (range, 19-97\%) (5, 6, 7, 8, 26, 27, 29, $30,31)$. The median fasting glucose levels at baseline were $5.2 \mathrm{mmol} / \mathrm{L}$ (range, 4.4-6.5), and median $\mathrm{HbA} 1 \mathrm{c}$ was $35.5 \mathrm{mmol} / \mathrm{mol}$ (34.4-36.8). The median mean value of LDL at baseline was $3.3 \mathrm{mmol} / \mathrm{L}$ (range, 2.8-3.7). Only 3 of 14 studies reported on baseline levels of sex hormones.
Records excluded $(n=29)$

Exclusions

$(n=6)$

Mixed surgical and medical treatment

$(n=3)$

Mixed etiology

$(n=2)$

Cross-sectional study $(n=1)$

Figure 1

Prisma flow chart.
The prevalence of comorbidities was not reported, or participants with comorbidities were excluded, in 12 studies.

\section{Assessment of risk of bias in included studies}

None of the included studies had a control group and the comparability item was left out. No participants were lost to follow-up in 9 of 14 studies $(4,5,25,26,28,30,31$, $32,33)$, in four studies $7-40 \%$ of participants were not included in final analysis $(6,8,27,29)$, and in one study this item was unclear (7). Based on our modified NOS bias assessment, we found that eight studies had a high risk of bias, and five studies had a lesser risk of bias in the 13 studies that reported on the primary outcome. Risk of bias for the primary outcome is presented in Table 1.

\section{Primary outcome: the effect of dopamine agonist therapy on weight or body mass index}

At follow-up, 12 studies reported change in BMI, one study reported change in weight exclusively and, finally, one study reported neither change in weight nor BMI. Therefore, 13 studies with 360 participants were available for analysis. The standardized mean change in BMI and 

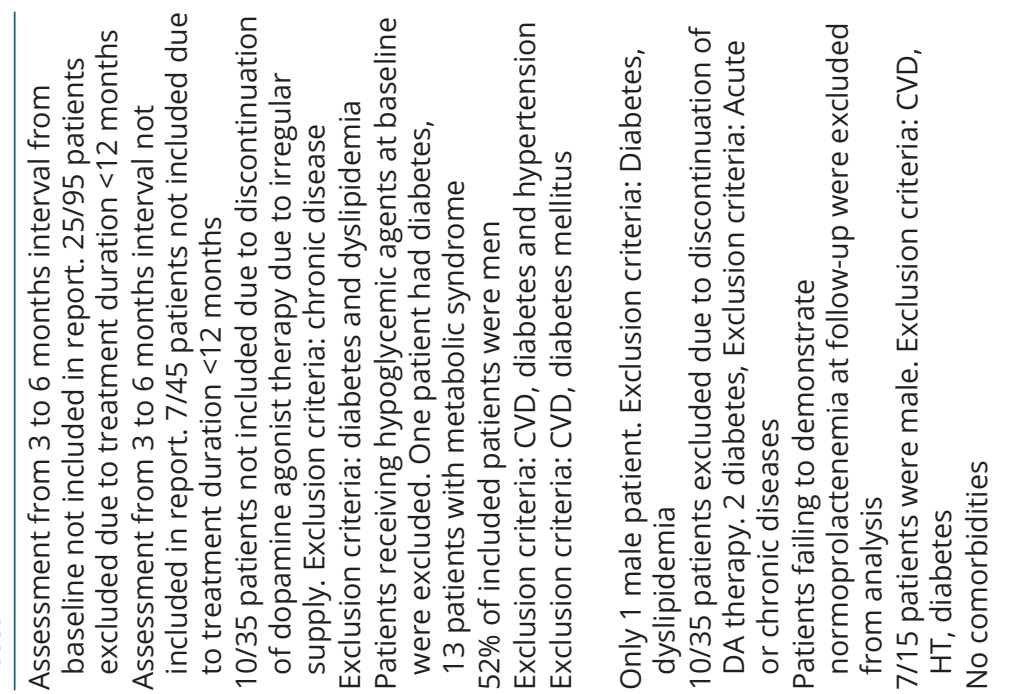

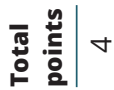

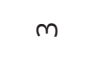

$m$

$\checkmark m m$

n $\rightarrow m+n O$

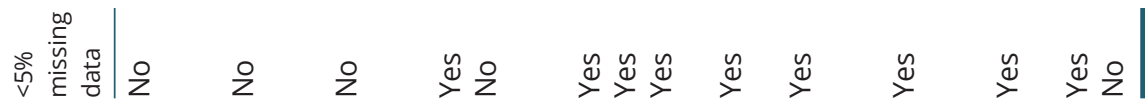

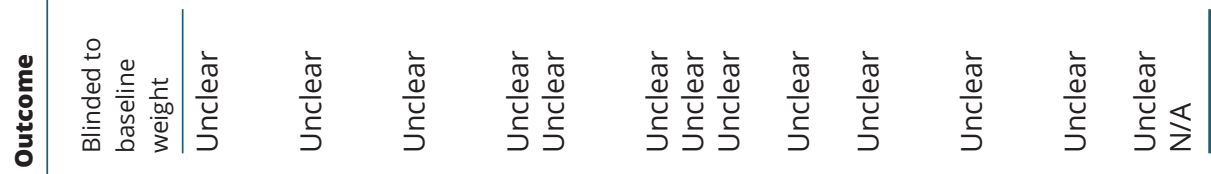

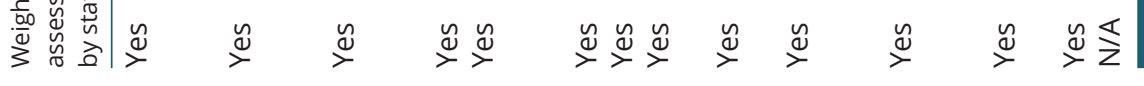

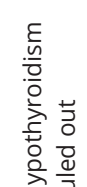

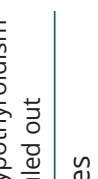

焉

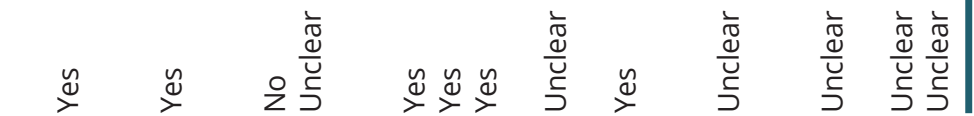

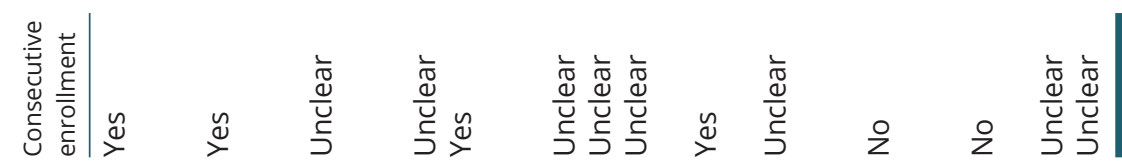

$\stackrel{4}{2}$

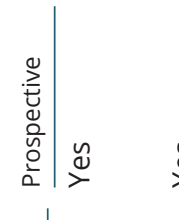

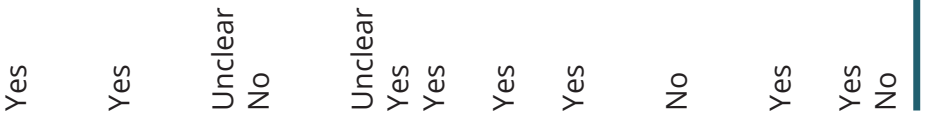

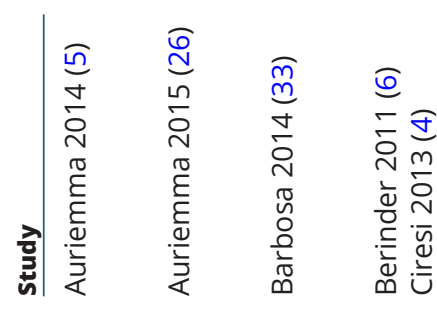




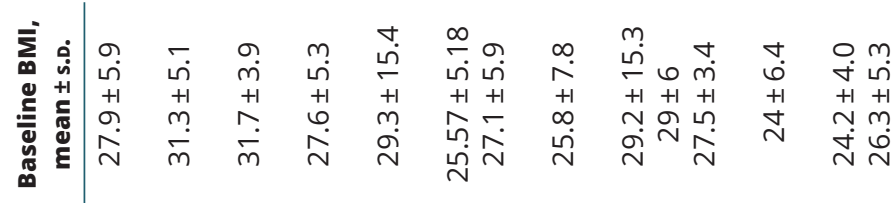

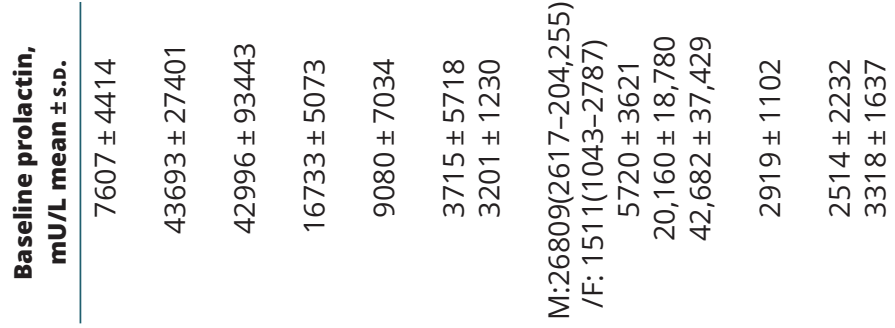

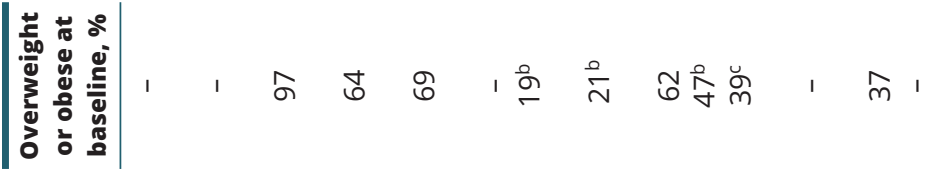

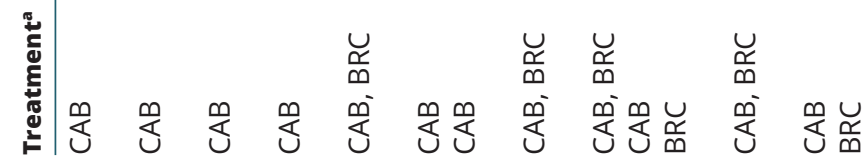

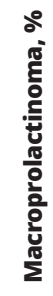

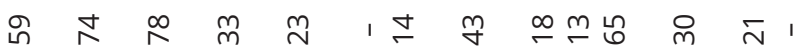

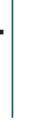

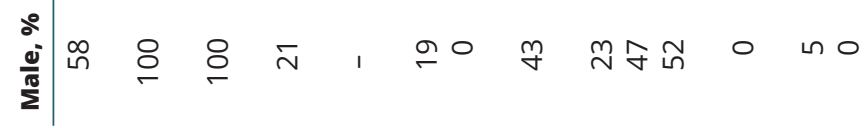

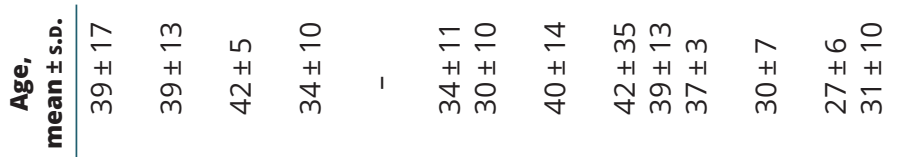

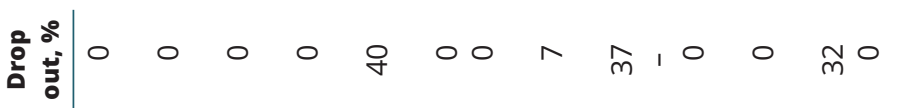

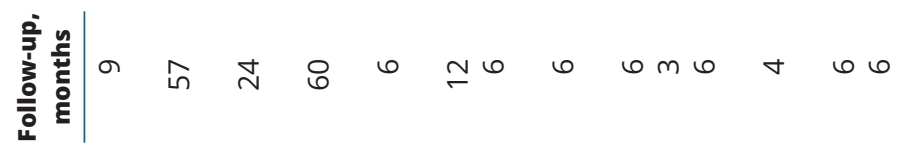

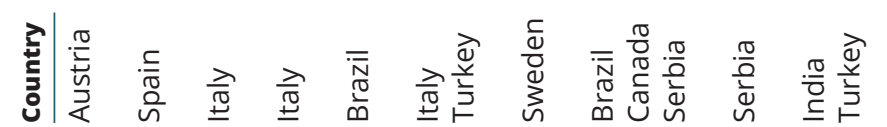

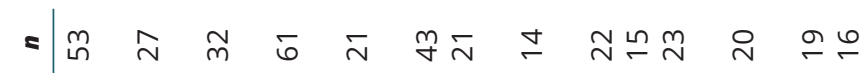

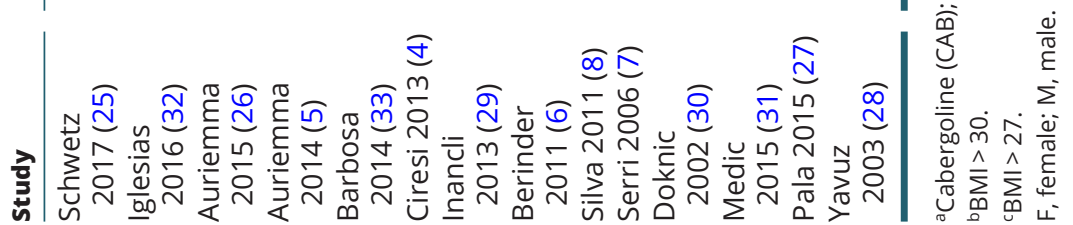




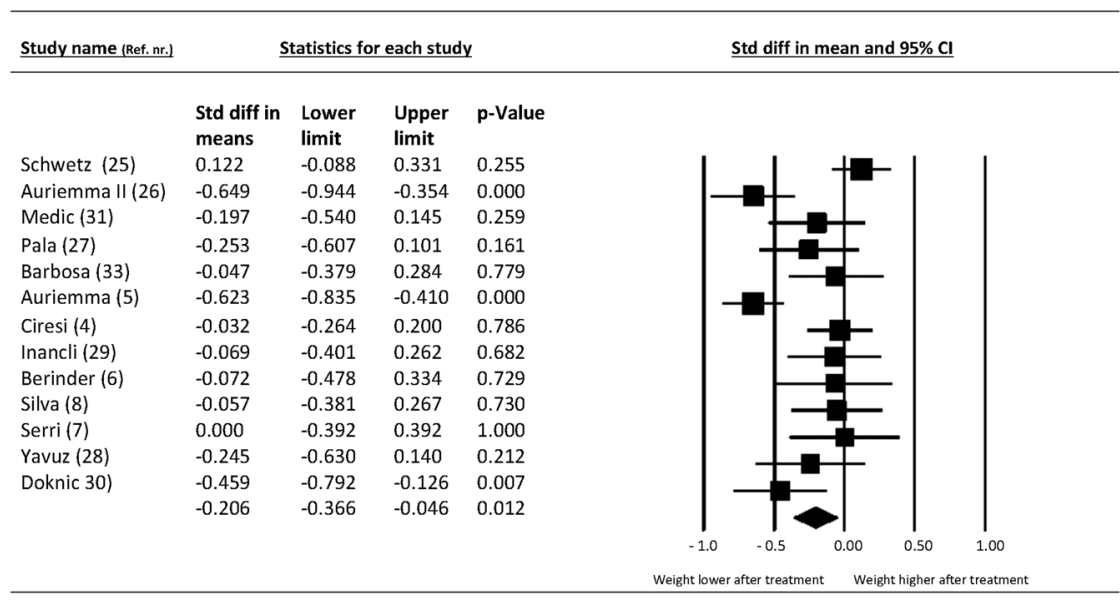

\section{Figure 2}

Change in weight/BMI after dopamine receptor agonist treatment in patients with prolactinomas. weight was $-0.21 \mathrm{SMD}(95 \% \mathrm{CI}-0.37$ to $-0.05 ; P=0.01)$ at follow-up compared to baseline values. For the 12 studies that only reported on BMI, the mean reduction in BMI after treatment was -1.17 BMI points (95\% CI -1.99 to -0.38). The forest plot is presented in Fig. 2 and inspection of funnel plot (not shown) for primary outcome did not suggest publication bias.

\section{Heterogeneity and subgroup analysis of primary outcome}

The primary outcome was associated with an $I^{2}$ of $71 \%$ suggesting substantial heterogeneity. Subgroup analysis suggested that the reduction of weight was $-0.09 \mathrm{SMD}$ (95\% CI -0.16 to $0.06 ; P=0.35 ; I^{2}=0 \%$ ) in studies with low prolactin levels at baseline compared to -0.33 SMD $(95 \%$ CI -0.58 to $-0.09 ; P=0.008 ; I^{2}=72 \%$ ) in studies with high prolactin levels at baseline. As shown in Supplementary Table 1, no other subgroup analyses explained the observed heterogeneity.

\section{Secondary outcomes}

After treatment with DA, the pooled SMD suggested a small decrease in WC, a small-to-moderate decrease in TRG, fasting glucose levels, HOMA-IR, HbA1c and hsCRP, and a moderate decrease in LDL, total cholesterol and insulin (Supplementary Table 2). There was no change in blood pressure, a small increase in LF and FSH, no increase in estrogen and estradiol and a large increase in testosterone after treatment.

\section{Adverse events from treatment}

Adverse events were reported in 4 of 14 studies. In one study, $24 \%$ of the patients had a transient gastrointestinal intolerance to DA treatment (29). In another study non-specified transient side effects occurred in 21\% (8). One study reported that no participants experienced adverse events (7) and in one study $87.5 \%$ of participants experienced nausea, dizziness and sleep disturbances during treatment (28). None of the studies reported serious adverse events.

\section{Discussion}

In this systematic review, we included 14 observational studies assessing the effect of DA treatment on metabolic variables in 387 patients with prolactinoma. For the primary outcome, weight and BMI, DA treatment significantly reduced body weight, with a weight reduction of $0.2 \mathrm{SMD}$. In addition, DA treatment was associated with small-to-moderate effects on all secondary endpoints except blood pressure, estrogen and estradiol. Too few studies reported on harmful events to provide any firm conclusions regarding this aspect of DA treatment in patients with prolactinomas.

A reduction in body weight was observed in 11 of 13 included studies; however, the effect was most prevalent in studies with high prolactin levels at baseline. In concurrence with previous reports $(17,34,35)$ the included studies had a high prevalence of obese participants at baseline which suggest an association between prolactin and obesity. There are several hypotheses, which may explain the observed reduction of weight after DA treatment in patients with hyperprolactinemia. One possible mechanism could be a direct effect of DA on metabolism. Randomized clinical trials of patients with type 2 diabetes and obesity suggest that quick-release BRC lowers HbA1c and fasting plasma glucose; however, in these studies a neutral effect on weight and lipid profile were observed $(36,37,38)$.

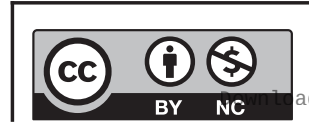


Hyperprolactinemia causes hypogonadotropic hypogonadism and the observed effect on weight may be a result of restoration of eugonadism. It is well established that obesity can cause male hypogonadotropic hypogonadism. By contrast, it is debated whether hypogonadism induces obesity. Some studies have shown that low testosterone levels reduce the fat-to-muscle ratio, but do not alter body weight $(39,40,41,42)$. In opposition to these results a RCT (43) and two observational studies examining changes in body weight in male patients with hypogonadism before and after initiation of testosterone treatment found a mean decrease in BMI of approximately four BMI points $(44,45$, 46). For women obesity has been associated with higher levels of estrogens $(41,47)$ but to our knowledge no studies looking at weight change related to treatment of secondary hypogonadism in women has been published.

A direct effect of prolactin on adipocytes and lipid metabolism cannot be excluded, since prolactin receptors have been identified on adipose tissue (48). However, one in vitro study on human adipocytes from women in the fertile age found that prolactin inhibited lipid storage outside breast tissue (16), thereby not supporting a link between obesity and prolactin. It should be emphasized that the design of the included studies in the present metaanalysis does not allow any conclusions on possible causal mechanisms between weight reduction and DA treatment.

For the secondary outcomes, we found improvement in all cardiovascular risk factors except blood pressure, estrogen and estradiol. We found a small decrease in WC, a small-to-moderate decrease in TRG, fasting glucose levels, HOMA-IR, HbA1c and hsCRP, and a moderate decrease in LDL, total cholesterol and fasting insulin levels.

DA treatment has a neutral effect on lipid profile (37). However, the favorable effect of quick-release BRC on glucose metabolism has led to the approval of BRC for treatment of type 2 diabetes by the FDA (49), and studies have found that BRC as add-on therapy in patients with type 2 diabetes lowers HbA1c (weighted mean difference, $-6.52 \mathrm{mmol} / \mathrm{mol}$; (95\% CI -8.07 to -4.97$)(37,50,51)$ which likely explains the observed effect on the glucose tolerance.

Reversal of hypogonadism might be contributing to the improvement in both lipid profile and glucose tolerance, but study results are conflicting: in a randomized double-blind trial allocating men with hypogonadism $(n=220)$ and type 2 diabetes or metabolic syndrome to testosterone supplementation or placebo; no consistent improvement was found in lipid profile or WC, but there was significant reduction in HOMA-IR (43). In two registry-based studies ( $n=255$ and $n=561)$ investigating males with hypogonadism, a significant reduction in total cholesterol, LDL, TRG, HbA1c, fasting blood glucose and CRP after testosterone treatment $(44,52)$.

There are several important limitations to the current review. No randomized trials were included, and all the reported outcomes were associated with moderate-tolarge heterogeneity. The strength of this review is that more than half of the included studies were prospective and the thorough and systematic approach regarding search strategy as well as data extraction and data synthesis. Furthermore, the protocol was made available in a publicly accessible database (Prospero) prior to data collection and analysis.

Today, large patient populations such as patients with renal failure and those receiving antipsychotic medication are not offered treatment for hyperprolactinemia. In case the findings from this systematic review could be replicated in studies of a higher evidence level, the clinical implications are potentially large.

\section{Conclusion}

This systematic review suggests a reduction of weight as well as an improved lipid profile and glucose tolerance after treatment with dopamine agonist in patients with prolactinomas. These data are based on low quality evidence.

\section{Supplementary data}

This is linked to the online version of the paper at https://doi.org/10.1530/ ERC-19-0292

\section{Declaration of interest}

The authors declare that there is no conflict of interest that could be perceived as prejudicing the impartiality of the research reported.

\section{Funding}

This research did not receive any specific grant from any funding agency in the public, commercial or not-for-profit sector.

\section{Acknowledgements}

Prospero number: CRD42016046525.

\section{References}

1 Haring R, Friedrich N, Völzke H, Vasan RS, Felix SB, Dörr M, Meyer Zu Schwabedissen HE, Nauck M \& Wallaschofski H. Positive association of serum prolactin concentrations with all-cause and cardiovascular mortality. European Heart Journal 201435 1215-1221. (https://doi.org/10.1093/eurheartj/ehs233)

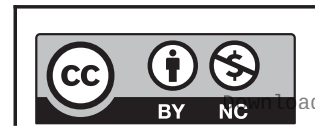

This work is licensed under a Creative Commons Attribution-NonCommercial 4.0 International License. aded from Bioscientifica com at 04/26/2023 06:57:23AM 
2 Krogh J, Selmer C, Torp-Pedersen C, Gislason GH \& Kistorp C. Hyperprolactinemia and the association with all-cause mortality and cardiovascular mortality. Hormone and Metabolic Research 201749 411-417. (https://doi.org/10.1055/s-0043-107243)

3 Toulis KA, Robbins T, Reddy N, Kumarendran B, Gokhale K, Wijesinghe H, Cheng KK, Karavitaki N, Wass J \& Nirantharakumar K. Males with prolactinoma are at increased risk of incident cardiovascular disease. Clinical Endocrinology 201788 71-76. (https:// doi.org/10.1111/cen.13498)

4 Ciresi A, Amato MC, Guarnotta V, Lo Castro F \& Giordano C. Higher doses of cabergoline further improve metabolic parameters in patients with prolactinoma regardless of the degree of reduction in prolactin levels. Clinical Endocrinology 201379 845-852. (https://doi. org/10.1111/cen.12204)

5 Auriemma RS, Granieri L, Galdiero M, Simeoli C, Perone Y, Vitale P, Pivonello C, Negri M, Mannarino T, Giordano C, et al. Effect of cabergoline on metabolism in prolactinomas. Neuroendocrinology 201398 299-310. (https://doi.org/10.1159/000357810)

6 Berinder K, Nyström T, Höybye C, Hall K \& Hulting AL. Insulin sensitivity and lipid profile in prolactinoma patients before and after normalization of prolactin by dopamine agonist therapy. Pituitary 201114 199-207. (https://doi.org/10.1007/s11102-010-0277-9)

7 Serri O, Li L, Mamputu JC, Beauchamp MC, Maingrette F \& Renier G. The influences of hyperprolactinemia and obesity on cardiovascular risk markers: effects of cabergoline therapy. Clinical Endocrinology 200664 366-370. (https://doi.org/10.1111/j.13652265.2006.02469.x)

8 Dos Santos Silva CM, Barbosa FRP, Lima GAB, Warszawski L, Fontes R, Domingues RC \& Gadelha MR. BMI and metabolic profile in patients with prolactinoma before and after treatment with dopamine agonists. Obesity 201119 800-805. (https://doi. org/10.1038/oby.2010.150)

9 Carrero JJ, Kyriazis J, Sonmez A, Tzanakis I, Qureshi AR, Stenvinkel P, Saglam M, Stylianou K, Yaman H, Taslipinar A, et al. Prolactin levels, endothelial dysfunction, and the risk of cardiovascular events and mortality in patients with CKD. Clinical Journal of the American Society of Nephrology 20127 207-215. (https://doi.org/10.2215/CJN.06840711)

10 Zhang L, Curhan GC \& Forman JP. Plasma prolactin level and risk of incident hypertension in postmenopausal women. Journal of Hypertension 201028 1400-1405. (https://doi.org/10.1097/ HJH.Ob013e328339f254)

11 Therkelsen KE, Abraham TM, Pedley A, Massaro JM, Sutherland P, Hoffmann U \& Fox CS. Association between prolactin and incidence of cardiovascular risk factors in the Framingham heart study. Journal of the American Heart Association 20165 e002640. (https://doi. org/10.1161/JAHA.115.002640)

12 Soto-Pedre E, Newey PJ, Bevan JS \& Leese GP. Morbidity and mortality in patients with hyperprolactinaemia: the PROLEARS study. Endocrine Connections 20176 580-588. (https://doi. org/10.1530/EC-17-0171)

13 Reuwer AQ, Twickler MT, Hutten BA, Molema FW, Wareham NJ, Dallinga-Thie GM, Bogorad RL, Goffin V, Smink-Bol M, Kastelein JJP, et al. Prolactin levels and the risk of future coronary artery disease in apparently healthy men and women. Circulation. Cardiovascular Genetics 20092 389-395. (https://doi.org/10.1161/ CIRCGENETICS.109.853572)

14 Simon-Holtorf J, Mönig H, Klomp HJ, Reinecke-Lüthge A, Fölsch UR $\&$ Kloehn S. Expression and distribution of prolactin receptor in normal, fibrotic, and cirrhotic human liver. Experimental and Clinical Endocrinology \& Diabetes 2006114 584-589. (https://doi. org/10.1055/s-2006-948310)

15 García-Caballero T, Morel G, Gallego R, Fraga M, Pintos E, Gago D, Vonderhaar BK \& Beiras A. Cellular distribution of prolactin receptors in human digestive tissues. Journal of Clinical Endocrinology \& Metabolism 199681 1861-1866. (https://doi.org/10.1210/ jcem.81.5.8626848)
16 Ling C, Svensson L, Odén B, Weijdegård B, Edén B, Edén S \& Billig H. Identification of functional prolactin (PRL) receptor gene expression: PRL inhibits lipoprotein lipase activity in human white adipose tissue. Journal of Clinical Endocrinology \& Metabolism 200388 1804-1808. (https://doi.org/10.1210/jc.2002-021137)

17 Perić B, Kruljac I, Šundalić S, Pećina HI, Jović A, Štefanović M, Butorac D \& Vrkljan M. Obesity and hypercholesterolemia in patients with prolactinomas: could DHEA-S and growth hormone be the missing link? Endocrine Research 201641 200-206. (https://doi. org/10.3109/07435800.2015.1135444)

18 Georgiopoulos GA, Stamatelopoulos KS, Lambrinoudaki I, Lykka M, Kyrkou K, Rizos D, Creatsa M, Christodoulakos G, Alevizaki M, Sfikakis PP, et al. Prolactin and preclinical atherosclerosis in menopausal women with cardiovascular risk factors. Hypertension 200954 98-105. (https://doi.org/10.1161/ HYPERTENSIONAHA.109.132100)

19 Reuwer AQ, Van Eijk M, Houttuijn-Bloemendaal FM, Van Der Loos CM, Claessen N, Teeling P, Kastelein JJP, Hamann J, Goffin V, Von Der Thüsen JH, et al. The prolactin receptor is expressed in macrophages within human carotid atherosclerotic plaques: A role for prolactin in atherogenesis? Journal of Endocrinology 2011208 107-117. (https://doi.org/10.1677/JOE-10-0076)

20 Landgraf R, Landgraf-Leurs MMC, Weissmann A, Hörl R, von Werder K \& Scriba PC. Prolactin: a diabetogenic hormone. Diabetologia 197713 99-104. (https://doi.org/10.1007/BF00745135)

21 Bahceci M, Tuzcu A, Bahceci S \& Tuzcu S. Is hyperprolactinemia associated with insulin resistance in non-obese patients with polycystic ovary syndrome? Journal of Endocrinological Investigation 200326 655-659. (https://doi.org/10.1007/BF03347025)

22 Melmed S, Casanueva FF, Hoffman AR, Kleinberg DL, Montori VM, Schlechte JA, Wass JAH \& Endocrine Society. Diagnosis and treatment of hyperprolactinemia: an Endocrine Society clinical practice guideline. Journal of Clinical Endocrinology \& Metabolism 2011 96 273-288. (https://doi.org/10.1210/jc.2010-1692)

23 Higgins JPT, Thomas J, Chandler J, Cumpston M, Li T, Page MJ, Welch VA. Cochrane Handbook for Systematic Reviews of Interventions version 5.2.0 (updated June 2017). London, UK: Cochrane, 2017. (available at: (http://training.cochrane.org/ handbook)

24 Hozo SP, Djulbegovic B \& Hozo I. Estimating the mean and variance from the median, range, and the size of a sample. BMC Medical Research Methodology 20055 13. (https://doi.org/10.1186/1471-2288-5-13)

25 Schwetz V, Librizzi R, Trummer C, Theiler G, Stiegler C, Pieber TR, Obermayer-Pietsch B \& Pilz S. Treatment of hyperprolactinaemia reduces total cholesterol and LDL in patients with prolactinomas. Metabolic Brain Disease 201732 155-161. (https://doi.org/10.1007/ s11011-016-9882-2)

26 Auriemma RS, Galdiero M, Vitale P, Granieri L, Lo Calzo F, Salzano C, Ferreri L, Pivonello C, Cariati F, Coppola G, et al. Effect of chronic cabergoline treatment and testosterone replacement on metabolism in male patients with prolactinomas. Neuroendocrinology 2015101 66-81. (https://doi.org/10.1159/000371851)

27 Pala NA, Laway BA, Misgar RA \& Dar RA. Metabolic abnormalities in patients with prolactinoma: response to treatment with cabergoline. Diabetology \& Metabolic Syndrome 20157 99. (https://doi.org/10.1186/ s13098-015-0094-4)

28 Yavuz D, Deyneli O, Akpinar I, Yildiz E, Gözü H, Sezgin O, Haklar G \& Akalin S. Endothelial function, insulin sensitivity and inflammatory markers in hyperprolactinemic pre-menopausal women. European Journal of Endocrinology 2003149 187-193. (https://doi.org/10.1530/eje.0.1490187)

29 Barbosa FR, Silva CM, Lima GA, Warszawski L, Domingues RC, Dominic M, Fontes R, Vieira Neto L \& Gadelha MR. Prevalence of obstructive sleep apnea in patients with prolactinoma before and after treatment with dopamine agonists. Pituitary 201417 441-449. (https://doi.org/10.1007/s11102-013-0524-y)

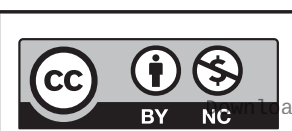

This work is licensed under a Creative Commons Attribution-NonCommercial 4.0 International License. ded from Bioscientifica.com at 04/26/2023 06:57:23AM 
30 Inancli SS, Usluogullari A, Ustu Y, Caner S, Tam AA, Ersoy R \& Cakir B. Effect of cabergoline on insulin sensitivity, inflammation, and carotid intima media thickness in patients with prolactinoma. Endocrine 201344 193-199. (https://doi.org/10.1007/s12020-0129857-y)

31 Doknic M, Pekic S, Zarkovic M, Medic-Stojanoska M, Dieguez C, Casanueva F \& Popovic V. Dopaminergic tone and obesity: an insight from prolactinomas treated with bromocriptine. European Journal of Endocrinology 2002147 77-84. (https://doi.org/10.1530/ eje.0.1470077)

32 Medic-Stojanoska M, Icin T, Pletikosic I, Bajkin I, NovakovicParo J, Stokic E, Spasic DT, Kovacev-Zavisic B \& Abenavoli L. Risk factors for accelerated atherosclerosis in young women with hyperprolactinemia. Medical Hypotheses 201584 321-326. (https:// doi.org/10.1016/j.mehy.2015.01.024)

33 Iglesias P, Villabona C \& Díez JJ. Concentraciones séricas de glucosa, colesterol y triglicéridos en varones con prolactinoma tratados con cabergolina. Medicina Clínica 2016147 466-467. (https://doi. org/10.1016/j.medcli.2016.05.025)

34 Greenman Y, Tordjman K \& Stern N. Increased body weight associated with prolactin secreting pituitary adenomas: weight loss with normalization of prolactin levels. Clinical Endocrinology $1998 \mathbf{4 8}$ 547-553. (https://doi.org/10.1046/j.1365-2265.1998.00403.x)

35 Korner J, Lo J, Freda PU \& Wardlaw SL. Treatment with cabergoline is associated with weight loss in patients with hyperprolactinemia. Obesity Research 200311 311-312. (https://doi.org/10.1038/ oby.2003.46)

36 Ramteke KB, Ramanand SJ, Ramanand JB, Jain SS, Raparti GT, Patwardhan MH, Murthy M \& Ghanghas RG. Evaluation of the efficacy and safety of bromocriptine QR in type 2 diabetes. Indian Journal of Endocrinology \& Metabolism 201115 S33-S39. (https://doi. org/10.4103/2230-8210.83062)

37 Liang W, Gao L, Li N, Wang B, Wang L, Wang Y, Yang H, You L, Hou J, Chen S, et al. Efficacy and safety of bromocriptine-QR in Type 2 diabetes: a systematic review and meta-analysis. Hormone and Metabolic Research 201547 805-812. (https://doi. org/10.1055/s-0035-1559684)

38 Manning PJ, Grattan D, Merriman T, Manning T, Williams S \& Sutherland W. Pharmaceutical interventions for weight-loss maintenance: no effect from cabergoline. International Journal of Obesity 201842 1871-1879. (https://doi.org/10.1038/s41366-0180165-3)

39 Grossmann M. Hypogonadism and male obesity: focus on unresolved questions. Clinical Endocrinology 201889 11-21. (https:// doi.org/10.1111/cen.13723)

40 Camacho EM, Huhtaniemi IT, O’Neill TW, Finn JD, Pye SR, Lee DM, Tajar A, Bartfai G, Boonen S, Casanueva FF, et al. Age-associated changes in hypothalamic-pituitary-testicular function in middle-aged and older men are modified by weight change and lifestyle factors: longitudinal results from the European Male Ageing Study. European Journal of Endocrinology 2013168 445-455. (https://doi.org/10.1530/ EJE-12-0890)
41 Escobar-Morreale HF, Santacruz E, Luque-Ramírez M \& Carretero JIB. Prevalence of "obesity-associated gonadal dysfunction" in severely obese men and women and its resolution after bariatric surgery: a systematic review and meta-analysis. Human Reproduction Update 201723 390-408. (https://doi.org/10.1093/humupd/dmx012)

42 Isidori AM, Giannetta E, Greco EA, Gianfrilli D, Bonifacio V, Isidori A, Lenzi A \& Fabbri A. Effects of testosterone on body composition, bone metabolism and serum lipid profile in middleaged men: a meta-analysis. Clinical Endocrinology 200563 280-293. (https://doi.org/10.1111/j.1365-2265.2005.02339.x)

43 Jones TH, Arver S, Behre HM, Buvat J, Meuleman E, Moncada I, Morales AM, Volterrani M, Yellowlees A, Howell JD, et al. Testosterone replacement in hypogonadal men with type 2 diabetes and/or metabolic syndrome (the TIMES2 study). Diabetes Care 2011 34 828-837. (https://doi.org/10.2337/dc10-1233)

44 Saad F, Yassin A, Haider A, Doros G \& Gooren L. Elderly men over 65 years of age with late-onset hypogonadism benefit as much from testosterone treatment as do younger men. Korean Journal of Urology 201556 310-317. (https://doi.org/10.4111/kju.2015.56.4.310)

45 Yassin A, Almehmadi Y, Saad F, Doros G \& Gooren L. Effects of intermission and resumption of long-term testosterone replacement therapy on body weight and metabolic parameters in hypogonadal in middle-aged and elderly men. Clinical Endocrinology 201684 107-114. (https://doi.org/10.1111/cen.12936)

46 Saad F, Haider A, Doros G \& Traish A. Long-term treatment of hypogonadal men with testosterone produces substantial and sustained weight loss. Obesity 201321 1975-1981. (https://doi. org/10.1002/oby.20407)

47 Seyfart T, Friedrich N, Kische H, Bülow R, Wallaschofski H, Völzke H, Nauck M, Keevil BG \& Haring R. Association of sex hormones with physical, laboratory, and imaging markers of anthropometry in men and women from the general population. PLOS ONE 201813 e0189042. (https://doi.org/10.1371/journal.pone.0189042)

48 Carré N \& Binart N. Prolactin and adipose tissue. Biochimie 201497 16-21. (https://doi.org/10.1016/j.biochi.2013.09.023)

49 U.S. Food and Drug Administration. Cycloset prescribing information. White Oak, MD, USA: FDA, 2009. (available at: http://www.accessdata.fda.gov/drugsatfda_docs/ label/2009/020866lbl.pdf)

50 Lopez Vicchi F, Luque GM, Brie B, Nogueira JP, Garcia Tornadu I $\&$ Becu-Villalobos D. Dopaminergic drugs in type 2 diabetes and glucose homeostasis. Pharmacological Research 2016109 74-80. (https://doi.org/10.1016/j.phrs.2015.12.029)

51 Bahar A, Kashi Z, Daneshpour E, Akha O \& Ala S. Effects of cabergoline on blood glucose levels in type 2 diabetic patients: a double-blind controlled clinical trial. Medicine 201695 e4818. (https://doi.org/10.1097/MD.0000000000004818)

52 Traish AM, Haider A, Doros G \& Saad F. Long-term testosterone therapy in hypogonadal men ameliorates elements of the metabolic syndrome: an observational, long-term registry study. International Journal of Clinical Practice 201468 314-329. (https://doi.org/10.1111/ ijcp.12319)

Received in final form 8 September 2019

Accepted 13 September 2019

Accepted Preprint published online 13 September 2019 https://ec.bioscientifica.com https://doi.org/10.1530/EC-19-0286 (c) 2019 The authors Published by Bioscientifica Ltd

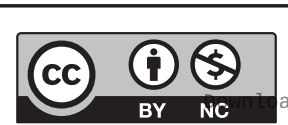

This work is licensed under a Creative Commons Attribution-NonCommercial 4.0 International License. ded from Bioscientifica com at 04/26/2023 06:57:23AM 